University of Windsor

Scholarship at UWindsor

OSSA Conference Archive

OSSA 5

May 14th, 9:00 AM - May 17th, 5:00 PM

\title{
Towards a Philosophy of Argument
}

J Anthony Blair

University of Windsor

Follow this and additional works at: https://scholar.uwindsor.ca/ossaarchive

Part of the Philosophy Commons

Blair, J Anthony, "Towards a Philosophy of Argument" (2003). OSSA Conference Archive. 8.

https://scholar.uwindsor.ca/ossaarchive/OSSA5/papersandcommentaries/8

This Paper is brought to you for free and open access by the Conferences and Conference Proceedings at Scholarship at UWindsor. It has been accepted for inclusion in OSSA Conference Archive by an authorized conference organizer of Scholarship at UWindsor. For more information, please contact scholarship@uwindsor.ca. 
Title: $\quad$ Towards a Philosophy of Argument

Author: $\quad$ J. Anthony Blair

Commentary: $\underline{\text { T. Govier }}$

(C) 2003 J. Anthony Blair

\section{Preliminaries}

Each of the terms 'argument' and 'argumentation' is defined in textbooks and the argumentation literature in a variety of ways. Most definitions focus on some particular aspect, element or perspective of a complex of concepts and activities. If philosophy consists, at least partly, of the activity of sorting out or classifying, defining, framing, and thereby clarifying the world for our understanding and action, as I think it does, then the philosophy of argument is in part the task of clarifying this complex. Any account will tend to abstract from the concrete, disorderly reality of the phenomena, and thus select and simplify. Still, the goal is to understand what argument is and how it works.

Jacobs observed that the activity of argumentation (perhaps we should say the many activities of argumentation) requires or presupposes at its heart or base the deployment of reasons taken to support claims. As he put it, "Arguments are fundamentally . . . entities that express with a special pragmatic force propositions where those propositions stand in particular inferential relations to one another” (2000, p. 264). Jacobs is referring to what I once called the "illative core" of argumentation - the "this, therefore that" which is a sine qua non of argument and argumentation. Even the broadest definitions of argument, such as those of Willard (1989 ) and Gilbert (1997), presupposes some element of reason-using. Otherwise what one has is simply a difference, as when you say "tomayto" and I say "tomahto," which is not a disagreement. Disagreements are over what is right or correct. If I say that your "tomayto" is the wrong pronunciation, then we have a disagreement and the possibility of argument. It is expected that there be reasons why one view is correct and its contraries incorrect. Whatever else is going on, without an illative core there is no argument and no argumentation.

However, I also called the illative core the smallest unit of argumentation, and in doing so I was conflating two distinct points. One is the point that Jacobs was making and that I have just underscored: illation is a necessary condition of argument or argumentation-hence the metaphor of the "core." However, what is the smallest unit of illation is another matter. Argumentation often includes any number of units of illation, chained together or running along independent lines, and there is nothing at the "centre" of all of them, even though all might lead in the same direction. So the metaphor of a "core" is misleading. When speaking of the smallest unit of illation, I think it is better to use the metaphor of the cell or the atom. So I now want to suggest that the smallest unit of argument consists of a reason to take (that is, maintain, adopt or change) an attitude towards a proposition, or towards an event or state of affairs or property, or towards an action or policy, and so on (in a broad sense of 'attitude'). I will call this an "atomic argument." An atomic argument is something that, taken by itself, does, or is taken to, or is offered to, imply or support a proposition, an attitude or an action. An argument supports a proposition, attitude or action if accepting the argument makes it more reasonable than otherwise 
to accept the proposition, adopt the attitude or do the action.

It is necessary to include the qualification, "taken by itself," because there can at the same time exist both an argument in favour of an attitude or action and also an argument against an attitude or action, so that the net effect of the two arguments is a stalemate. Still, either one, taken by itself, will have made the attitude or action more reasonable than otherwise. Also, there can be two or more arguments in favour of an attitude or action, such that any one of them makes it completely reasonable and so adding a second one could not possibly make the attitude or action more reasonable. Still, absent of all the others, any one of them, taken by itself, will make the attitude or action more reasonable than otherwise.

It is necessary to add the qualification "than otherwise," because something can be an argument for an attitude or action without making it completely reasonable to adopt the attitude or perform the action.

By 'attitude' I mean to include epistemic attitudes such as degrees of belief, but also nonepistemic attitudes such as degrees of liking or favouring, degrees of supporting, degrees of commitment, degrees of commendation, and the like. By an attitude towards an event or a state of affairs or a property I mean such things as approving or disapproving of it to some degree, wanting it to occur or not to occur, liking or disliking it, and valuing or disvaluing it. By an attitude towards an action or policy I mean such things as approving or disapproving it, prescribing or endorsing it or the opposite, and choosing it or rejecting it. So when I speak of "adopting” an attitude, I mean to include not only such things as moving from unbelief to belief or conversely, or changing one's degree of conviction, but also such things as coming to approve or disapprove, or changing one's degree of approval or disapproval, and so on. By 'action' I mean not just act-tokens but also policies or rules, and the like. So when I speak of "doing” or "performing" an action I mean to include as well making a decision, approving or implementing a plan, policy or regulation, and so on.

The extent to which there are or can be reasons for such things is a matter of philosophical debate. My point is that if there can be such reasons, the smallest unit of such reason is an atomic argument. This is not the place to settle the larger philosophical questions that are pertinent here. So the concept of argument should not be specified in a way that begs any of these questions. It should not close off, just by the definition of argument, the possibility of arguing for one or another of these things.

By a reason I do not mean a premise as the latter term is usually understood. Usually a premise is taken to consist of a single proposition. A reason may consist of several propositions, that is, of a conjunction of propositions, or of other vehicles for conveying reasons, if others there be. A reason can be a proposition or group of propositions that stands in the relation to some other proposition. But there can be reasons for decisions or actions, and decisions or actions are not propositions. So reasons mustn't be conceived in such a way that there cannot be reasons for actions, since clearly there can be. Can there be non-propositional reasons? It seems that sensory experiences can serve as reasons, or partial reasons, for beliefs. One's gestalt impression of a person can serve as a partial reason to take an attitude towards that person, perhaps of trust or of distrust, of sympathy or hostility. Also, an emotion, such as fear, can serve as a partial reason for an action, such as flight; love can serve as a partial reason for an action, such as marriage; and so on. So rather than presuppose that only propositions can serve as reasons, I will speak more generally of “considerations.” A reason is constituted by whatever considerations prima facie justify a modification in either the direction or the intensity (or both) of the attitude or action. 
Two or more considerations belong to the same reason just when, although singly they do not constitute reasons, their conjunction constitutes a reason.

Any two offered reasons constitute two distinct atomic arguments just when, if either turns out not to count as a reason, the other, without inconsistency, could count as a reason.

A group of considerations may be taken to be or may be presented as an atomic argument although they do not constitute an argument at all. In that case, they are irrelevant, although the person offering them might have erroneously thought that they were relevant, or might have thought that the audience to which he addressed them would erroneously think that they were relevant. Whether what is offered as an argument is an argument can be a subject of controversy. So we say such things as, "Her argument was irrelevant," when what we mean more precisely is, "What she took to be (or offered as) an argument was not an argument because what she took (or offered) as reasons for the claim in question were irrelevant."

We identify as arguments considerations that make attitudes or actions more reasonable than otherwise whether or not they are recognized as such. So there can be arguments that not everyone understands, and there can be arguments that have only just been discovered or invented, yet once identified can make a past attitude or action correct, or mistaken. However, as just noted, we also identify as arguments things that are taken to make an attitude or action more reasonable even though they do not, and things that are offered as making an attitude or action more reasonable although they do not. Otherwise we could not speak of people adopting logically bad arguments or deliberately using logically bad arguments. A logically bad argument is an argument either unintentionally or deliberately taken to make, or offered as making, an attitude or action more reasonable when it does not do so.

Atomic arguments are prima facie reasons when an atomic argument in one direction is consistent with an atomic argument in a different direction. For example, there can be an atomic argument in favour of adopting a point of view when there is also an atomic argument in favour of rejecting it, or an atomic argument that a point of view should be firmly adopted when there is also an atomic argument that a point of view should be only tentatively adopted.

We might, following Pinto (2001) (and Beardsley, 1976, 5), think of offering an atomic argument as inviting another or others to take something to be an atomic argument, that is, to take its considerations as reasons to take an attitude or action-in other words, to infer the attitude or action in question from the considerations it adduces.

A group of considerations constituting an atomic argument can belong anywhere on a continuum from weak argument to strong. Atomic arguments can be weak or strong in either of two dimensions. First, assuming that there is no question or doubt about the truth or acceptability of the considerations adduced, they may present justifications that have varying degrees of force. Second, there can be varying degrees of confidence in the truth or acceptability of those considerations, whatever their justificatory force would be if they were true or acceptable. The strength of atomic arguments in either dimension can be a subject of controversy.

Atomic arguments are used for any of a number of purposes (to be discussed), and in the process they are regularly used in groups and in combinations. The logical merits of groups or combinations of atomic arguments are partly a function of their individual logical merits, but also a function of the comparative logical merits of different groups or combinations. An atomic argument supporting taking a particular attitude or action can itself be supported by one or more further atomic arguments, and these can in turn be similarly supported, and so on, indefinitely. I call such a chain of atomic arguments a line of argument for the ultimate attitude or action. An attitude or action can be supported by more than one line of argument supporting it, in light of 
more than one line of argument against contrary attitudes or actions, together with a "balance of considerations" argument that weighs the relative strengths of all the pro and con lines of argument. Such a complex of atomic arguments supporting an "all-things-considered" attitude I call $a$ case for that attitude.

Atomic arguments can be discovered, assembled, invented, or borrowed.

\section{Uses of arguments}

The term 'argumentation' is used so variously and loosely in the literature that any definition will be a stipulation. However, some recent accounts run along similar lines. Van Eemeren, Grootendorst, and Snoeck Henkemans $(1996,5)$ characterize argumentation as “a verbal and social activity aimed at increasing (or decreasing) the acceptability of a controversial standpoint for the listener or reader, by putting forward a constellation of propositions intended to justify (or refute) the standpoint before a rational judge.” Goldman $(1999,131)$ calls argumentation the activity of presenting arguments to an audience, whereby someone asserts and defends a conclusion by appeal to the premises. Johnson $(2000,12)$ calls (the practice of) argumentation the socio-cultural activity of constructing, presenting, interpreting, criticizing and revising arguments. All of these accounts take argumentation to be the use of arguments. The first two tie argumentation to particular uses of arguments; the third does not specify any particular purpose for the activity.

I will follow these accounts and use 'argumentation' to denote any activity involving the use of atomic arguments, lines of argument or argument cases, and to denote such arguments when they are being or have been so used. So we can speak of analyzing someone's argumentation, when what we mean is that we shall identify the nexus of atomic arguments that she used for a particular purpose. And the atomic arguments traded in an argumentative discussion will constitute its argumentation.

It seems to me that arguments can be put to any number of intrinsic uses. They certainly can be used try to convey knowledge and its grounds (the use Goldman has in mind) or to try to alter someone's opinion (the use that van Eemeren, Grootendorst and Snoeck Henkemans, and that Johnson, have in mind). They can also be used to try to demonstrate knowledge (for instance, when students are expected to produce or reproduce arguments in examination answers). They can be used to try to persuade an audience to take an action or adopt a policy. They can be used to explore the pros and cons of a position with a view to deciding what attitude to take or action to perform. They can be used as a means of resolving conflicts. I call these intrinsic uses because in these uses arguments are integral to realizing the objective. The point is not that one cannot (try to) achieve these ends in other ways; it is that (usually) what is wanted is that these ends be achieved by means of arguments.

Such uses of arguments can at the same time have other objectives. For instance, one might want to persuade someone to change her mind about something and at the same time maintain her friendship or respect, or at the same ensure that she will be amenable to future persuasion, or at the same time impress her with one's cleverness or erudition. These might be called associated or incidental uses of argument, since these are objectives that might as well be sought and achieved in other ways than by using arguments, but can be aimed at along with an intrinsic use of arguments.

To be distinguished from both intrinsic and associated uses of arguments are uses of 
arguments to achieve some end for which arguments are not particularly designed. Think of using a tool, such as a screwdriver. A screwdriver's intrinsic use is to drive screws into some substance. One might use a screwdriver at the same time to impress someone with one's dexterity or to demonstrative that one's arthritis is not debilitating. These are associated or incidental uses. But one might also use a screwdriver for some purpose for which it was not designed-as a pry, a wedge or a chisel, for example: what might be called extrinsic uses. Arguments can be put to extrinsic uses. For example, arguments might be used to filibuster, or to intimidate someone, or to distract someone, to bore someone so they depart, to insult someone, and so on.

In communicating arguments to others, a person can be addressing one particular person, or a particular group of people, small or large, or anyone who might listen to or read the arguments. Typically, atomic arguments are presented to another person or persons with a view to modifying their attitude or inducing action, but they can also be presented to one audience with a view to changing the attitude or decision of some third party.

\section{Norms relative to uses}

Given the various types of intrinsic purpose for which arguments can be and are used, it is to be expected that (at least slightly) different norms will be appropriate for each such use. Consider a number of instances.

If atomic arguments, singly or in groups, are used to convey knowledge, it is to be expected that the considerations serving as reasons will themselves be known or reasonable to believe, and that the arguments used will indeed strongly support the knowledge-claims they are used to support. Thus, the reasons offered will be expected either to entail or to provide strong inductive support for the claims based on them. Also, one would expect appeals to testimony or authority to meet norms designed to maximize the chances that accurate information will be conveyed. And so on.

Goldman $(1999,134)$ develops a set of such rules, among which are the following:

(1) the speaker believes the asserted conclusion;

(2) the speaker believes each of the asserted premises;

(3) the speaker is justified in believing each of the asserted premises;

(4) the asserted premises jointly provide strong support for the conclusion.

If atomic arguments are used in dialogues aimed at rationally resolving a difference of opinion, it is to be expected that arguments will appeal to common ground (mutually acceptable reasons) that support by mutually acceptable reasoning an attitude both parties will endorse. There will be norms governing the interchange of arguments aimed at maximizing the chance of an agreement. See rules of the sort van Eemeren and Grootendorst develop (e.g., 1996, 283-284), among which are the following:

(1) Parties must not prevent each other from advancing standpoints or form casting doubts on standpoints.

(2) A party that advances a standpoint is obliged to defend it if asked by the other party to do so. 
(3) A party's attack on a standpoint must relate to the standpoint that has indeed been advanced by the other party.

(4) A party may defend a standpoint only by advancing argumentation [my atomic arguments] relating to that standpoint.

If atomic arguments are used in monologues by one person rationally to persuade others, then it will be expected that the arguments will satisfy norms of reasonableness, and that the arguer will use arguments to try to remove any questions or doubts that the audience can be expected to harbour. See the norms that Johnson develops (2000, Ch. 7): the acceptability, truth, relevance and sufficiency requirements, and rules of good process.

If atomic arguments are used by a person to decided for herself or himself what to believe or do in connection with a particular issue, the arguments should include those offered by proponents of the various alternatives, as well as any the person can generate based on her or his own experience. Any considerations the person finds problematic (that is, questionable, improbable or implausible, given her or his background knowledge) would themselves have to be tested in turn by considering arguments for and against them. And so on. See, for example, Meiland's “steps in an argumentative paper (1981, 62-66).

If atomic arguments are used to persuade independently of the arguer's commitment to them (that is, commitment to the truth or acceptability of their reasons or to the force of their reasons as support for the attitude in question), then the norms will be a function of what the market will bear. Appeals to the prejudices of the audiences, to erroneous beliefs or other unjustified attitudes the audience holds, will be permissible up to the point that it becomes counter-productive to use them (such as if the risk of exposure outweighs the benefits of persuasion). Thus, the informal norms will be prudential. There are also conventional restraints on such uses of argument in various situations. For example, the rules applicable to criminal trial pleadings, the rules of debating games, the rules of parliamentary debate, the legal rules governing political campaigns, the legal restrictions on advertising - all impose restrictions on the lengths to which the arguer may go in trying to persuade the relevant audience, presumably with a view to protecting the integrity of the argumentative practice in each case.

To the extent that different uses of atomic arguments share properties, it is to be expected that the norms appropriate to them will be shared.

The use of atomic arguments is often an action affecting others, and as such is subject to the norms of individual, social and political morality. But these are not norms governing arguments or their use in particular, but actions in general, of which the uses of arguments are types.

\section{Norms of different perspectives on arguments}

Independently of their intrinsic uses, arguments can also be assessed from different perspectives. I have in mind the logical, dialectical, and rhetorical perspectives.

Each atomic argument's reasons can be assessed for their truth, probability, plausibility or acceptability relative to the purposes at hand. And each atomic argument's reasons can be assessed for the strength of the support they supply for the attitude at issue. These are factors affecting the logical merits of an argument. Considering the strength, for example, it can be asked whether the reasons entail the attitude (whether the inference from the reasons to the 
attitude is deductively valid). If they do not, it can be asked whether the reasons make the attitude probable (or as probable as it is claimed they do), or plausible (or as plausible as it is claimed they do). For different purposes, different logical norms for the reason-attitude link will be appropriate. If one is trying to prove that a proposition is true, then showing that it is entailed by other true propositions makes the strongest case, followed by showing that it is highly probable, given all the available evidence. If one is trying to show that someone should consider performing a given action, then showing that there is a presumption in its favour might constitute a logically good argument. And when evaluating a line of argument, or a case for a position, the logical merits of each individual atomic argument component needs to be investigated.

When an argument is used in any of the ways that entail interacting with the views of other people, it can be asked how adequate the interaction is for the purposes at hand. For example, in the case of dialogical argumentation, if one wants another person to adopt an opinion on a particular standpoint, it will be otiose to use arguments prior to discovering whether the person in fact holds a different opinion with respect to that standpoint. Having established that there is a difference of opinion, if one's goal is to resolve the disagreement rationally, one will need to argue against the opinion the interlocutor actually holds, and not against some deceptively similar opinion with a view to deceiving the interlocutor. Also, the arguer will have to answer whatever objections the interlocutor raises. In the case of monological rational argumentation (that is, one arguer presenting arguments to a non-interacting audience), there will need to be norms governing how extensively the arguer must canvas and reply to objections. There will be many other factors to consider when assessing arguments from this dialectical perspective. Often, perhaps usually, a condition of dialectical adequacy will be that the atomic arguments used are logically adequate, but it is possible to imagine uses of argument in which dialectical rejoinders might be effective even when logically faulty.

The question of the effectiveness of a use of arguments brings us to the rhetorical perspective, insofar as rhetoric is conceived at least in part as the art of effective communication and the use of arguments as a type of communication. Any properties of argumentation that bear on the effectiveness of its communication will be rhetorical properties, and the assessment of how effective the communication of arguments and argumentation is will be a rhetorical assessment. On this conception, the rhetorical perspective does not apply when arguments are used in a way that does not entail interaction with others, but purely to inquire, or to establish attitudes without regard for any interlocutors. (Perhaps there are no such cases.) However, in many uses the arguer will have it as a communicative purpose that arguments play some role or another. So, for example, if their persuasiveness with the audience is affected by the ordering of the arguments, then their order is a rhetorical property. Arguments can be ordered well or poorly. The arguer presents himself or herself to the audience in such a way as to enhance or inhibit its receptiveness of the argumentative message, so the ethos of the arguer in the situation will be a rhetorical property. To the extent that the emotional state of the audience can make it more receptive to the arguments on offer, the arguer can take advantage of, or try to create, such a conducive emotional state, so the pathos of the argument will be a rhetorical property. To be sure, in most situations logically sound arguments will be more effective than unsound ones, and argumentation will be more effective if it is dialectically thorough than if it is dialectically incomplete. So, in those situations, logical and dialectical properties will also be rhetorical ones. The point of view of the assessor is a variable that can bear on the relevant norms to be used in assessing arguments. For instance, someone designing the presentation of arguments to persuade an audience will want to be sure to use effective rhetoric; whereas a person to whom 
the persuasion is addressed will want to appreciate its rhetoric in order to discount it when necessary and not to be improperly influenced by it, should that be a possibility.

5. The emphasis on given norms relative to users

Different users will have interests in different properties of arguments. As one to whom an argument is addressed inviting your adherence to the conclusion or your support for an action, you will presumably be interested in its having sound logic and thorough dialectical coverage. You want to form a judgement or make a decision based on good reasons, and on all the relevant considerations. As someone who is producing an argument, scanning the rhetorical situation will be your initial priority, and refining the rhetorical virtues of the case your final task, with good logic and dialectic occupying your time in between. You want to be sure that your argument addresses the theoretical and practical interests and needs of your audience and the occasion. Depending on her interests, the scholar or critic or editor might place emphasis on different combinations of properties in evaluating an argument or a case.

\section{Fallacies}

On the conception of argument being proposed, there will be no single theory of fallacies. The character of particular fallacies will be a function of the use of argument in question. According to the Pragma-Dialectical theory, the abusive ad hominem is an illegitimate attempt to block an interlocutor from engaging in an argumentative discussion, and as such is a dialectical fallacy (see van Eemeren and Grootendorst, 1992, 110-113). According to the use of argument to transmit knowledge, the use of an abusive ad hominem to block an objection is an epistemic fallacy, since it impedes consideration of a factor that might bear on the truth of the claim in question (see Goldman, 1999, 152). Similarly, the fallacy of begging the question can be given either a dialectical or an epistemic interpretation. In a dialogue designed to resolve a disagreement, it is dialectically illegitimate to appeal to the very point at issue, since that is what the interlocutor is denying, so begging the question is a dialectical fallacy. In an argument aimed at establishing the truth of a proposition, it is illegitimate to appeal to that proposition, since the assumption is that the proposition requires support; so begging the question is an epistemic fallacy. To argue that all fallacies are dialectical in nature or that all fallacies are epistemic in nature or that all fallacies exhibit some other basic characteristic is to overlook alternative uses of arguments, or to attempt to elevate one to the exclusion of all others.

\section{Types of argument}

On the conception of argument being proposed, there are not different types or modes or models of argument or argumentation, but rather different uses of argument and different perspectives in the light of which to interpret and assess arguments and argumentation. Thus, on this conception it makes no sense to contrast the logical mode of arguing with the emotional mode of arguing (as does Gilbert, 1997, 79), or the logical model of argumentation or the dialectical model of argumentation with the rhetorical model of argumentation (as does Tindale, 
1999, 207).

I think what Gilbert is interested in establishing is the claim that emotions can legitimately play a role in arguments. I would agree that there are arguments in which emotions are relevant in various ways, but it confuses things to denominate these as the "emotional mode" of argument in some sense that contrasts them with the "logical mode" of arguing, as Gilbert seems to want to do. It seems clear that the fact that someone is angry or upset or anxious or fearful is relevant to him as a consideration in his deciding what to do, and in such cases it does and should play a logical role. To contrast emotion and logic is therefore misleading. It also seems clear that the emotional state of the audience of an argument will affect how the argument is received and so plays a rhetorical role. In any case, the debate about whether emotions are or can be reasons for acting, or for believing, belongs to action theory, or epistemology, respectively, not to the theory of argument, on the conception of argument I am proposing.

To speak, as Tindale does at times, of rhetorical argumentation-as contrasted with logical argumentation-risks overlooking the consistency of rhetoric and logic. I have suggested that one will want one's logically impeccable arguments addressed to others to affect their attitudes, and so will want to attend to the properties of the situation of the argument, including the audience and the occasion (among other things), and consequently to consider what argument selection, ordering, presentation (and so on) that will best attain that end. Similarly, I have suggested that there will be (many) contexts in which the most effective way to attain one's communicative goals involving the use of arguments will be to make sure that the arguments one offers are logically sound. Tindale suggests that rhetoric is more important or more fundamental than logic or dialectic, and by that he seems to mean that in order to achieve one's argumentative goals, one must first assay the rhetorical context, and adapt one's logic and dialectic to that context. I think this is right for some uses of argument, but wrong for others. One can think of situations in which the arguer's overriding objective is to have logically good and dialectically complete arguments. To be sure, this claim presupposes that logical and dialectical goodness can be identified independently of rhetorical properties (such as the beliefs and attitudes of an audience) in such situations. I cannot think why one would want to deny such a possibility $a$ priori, and granting this point, it would have to be granted that such situations are at least in principle possible. In using arguments to help oneself decide what position to take on a pressing issue, for example, the rhetorical perspective does not come into the picture. Suppose I am trying to decide what my position should be on whether the names and current addresses of convicted child-molesters who have served out their prison sentences should be made public. I need to consider all the arguments on both sides that I can find or generate myself, assess the logical merits of those arguments, and come to an all-things-considered judgement. I might want to do this with no intention of mentioning my view on the matter to anyone else. The effectiveness of my communication is not a factor since I do not (intend to) communicate it. To be sure, I will need to understand the rhetorical properties of the discourse in which I find the arguments that I need to examine. But the interpretive moment is distinguishable from the judgement-formation moment. So while it is important to emphasize the centrality of the rhetorical perspective, as Tindale has done, it seems a mistake to elevate any one perspective to primacy in all possible uses of arguments.

A similar objection might be developed against van Eemeren and Houtlosser's (2000) attempt to relegate the logical and rhetorical perspectives to subservience to the dialectical perspective. 


\section{Competing schools}

It should be evident from what has been argued so far is that Goldman is mistaken to reject the Pragma-Dialectical model of argument for failing to function well as an account of argument used to transmit knowledge (Goldman, 1999, 159-160). Goldman produces a list of standards of good argument and argumentation based on the point of argument being to establish the truth of a proposition and the point of argumentation being to maximize veritistic valuesroughly, knowledge and freedom from error (see 1999, 87-94). He then criticizes the PragmaDialectical model, which is based on the point of argumentation being to rationally resolve a disagreement, for failing to meet veritistically-grounded norms of argumentation. He does not argue that veritistic goals are the only proper goals for argumentation, or that disagreementresolution is an improper goal of argumentation.

And it would be equally mistaken for van Eemeren, et al., to reject Goldman's epistemic model for failing to function well as an account of argument used to resolve a difference of opinion, should they be tempted to do so. I think it also follows from the conception of argument being proposed that the Pragma-Dialectical model is not fruitfully superimposed on all uses of argument for purposes of analysis or assessment. The Pragma-Dialectical model was designed for the use of arguments to resolve a disagreement rationally. On the face of it, there are other, different, equally legitimate uses of arguments. It would be surprising if the norms of the disagreement-resolution use of arguments applied in every other use.

A somewhat weaker claim than that the Pragma-Dialectical model is the ideal type in terms of which all argumentation should be analyzed and evaluated is the claim that all uses of arguments can be modelled as dialogues. That would be another way of saying that the dialectical perspective is always applicable to arguments. I can see that the dialectical perspective often applies when two or more atomic arguments are chained together in a line of argument, or when two or more lines of argument are generated in a case. What motivates a second atomic argument is frequently some question about or challenge to the first, and such a question or challenge is then readily and helpfully modelled as a turn in an argumentative dialogue. But the dialectical perspective does not apply to individual atomic arguments. Whatever dialectical considerations might motivate the formulation or presentation of an individual atomic argument, its logical virtues will be independent of its dialectical function in any line of argument.

Some proponents of Pragma-Dialectics seem to be committed to the view that in supplying a second consideration to a reason one is always responding to a dialectical critique (Snoeck Henkemans, 1992, sometimes seems to suggest this). But an arguer can present a reason that has no missing considerations, without being prompted by an interlocutor to do so; and presenting such a complete atomic argument does not necessarily presupposes challenges to the relevance of any of its elements taken by itself. Suppose I am dubious about $r$, and you, seeing that $p$ and $q$ entail $r$ and believing you can persuade me of $r$ by pointing out that fact, present me with the argument, " $r$, because $p$ and $q$." If supplying both premises betrays anticipation of an objection to the relevance of one of them taken by itself, which one of $p$ and $q$ did you think I might have challenged? It is perfectly plausible that you see that $p$ and $q$ jointly entail $r$, and so offer the pair as an open-and-shut case for $r$. Again, it is sometimes argued that any time there is a line of argument-a reason with one of its considerations backed by a further reason - that is so because the arguer has anticipated (or received) an objection and is producing an additional atomic argument to refute the objection. I think that is often the case, but it need not always be 
so. Suppose, for example, that you want me to believe $r$, which I resist, and the following story is also true. You know that I believe $p$, and in your opinion: (a) $p$ implies $q$, (b) I will recognize that $p$ implies $q$ if you point it out to me, (c) $q$ implies $r$, and (d) I will recognize that $q$ implies $r$ if you point it out to me. So you present me with the following line of argument: " $r$, because $q$, and $q$ because $p$." Did you offer the atomic argument “ $q$ because $p$ ” because you wanted to argue " $r$ because $q$ " but you thought I would balk at $q$ ? Not as I am imagining your reasoning. As I am imagining your reasoning, you notice that $p$ supports $r$, but only indirectly, by way of directly supporting $q$, which in turn directly supports $r$. So while a line of argument can reflect an actual or anticipated dialectical interchange, it doesn't have to.

The general point is that the attempt to assimilate all argumentation to a single use as the exemplar or primary is misguided. My prediction is that any such attempt will run into the sort of detailed objection just demonstrated, and is motivated by undue emphasis on a single use of argument.

\section{Conclusion}

What I have tried to sketch is a conception of argument and argumentation that is consistent with arguments being put to a wide range of uses and that frees the definition of argument from association with any particular use. I have suggested that some of the controversies that have occurred in the recent argumentation literature are based on a failure to distinguish different uses of arguments, or else (or as well), a confusion of modes or models of arguments with perspectives on argument. The conception of argument I am proposing is in an important respect pluralistic, and is hostile to the attempt to reduce the variety of models or uses of arguments to any single one.

\section{References}

Beardsley, Monroe C. 1976. Writing With Reason. Englewood Cliffs, NJ: Prentice-Hall.

Eemeren, Frans H. van and Rob Grootendorst. 1992. Argumentation, Communication and fallacies: A Pragma-Dialectical Perspective. Hillsdale, NJ: Lawrence Erlbaum Associates.

Eemeren, Frans H. van, Rob Grootendorst and A. Francisca Snoeck Henkemans (Eds.). 1996. Fundamentals of Argumentation Theory: A Handbook of Historical Backgrounds and Contemporary Developments. Mahwah, NJ: Lawrence Erlbaum Associates.

Eemeren, Frans H. van and Peter Houtlosser. 2000. "Rhetorical Analysis Within a PragmaDialectical Framework,”Argumentation 14: 293-305.

Gilbert, Michael A. 1997. Coalescent Argumentation. Mahwah, NJ: Lawrence Erlbaum Associates.

Goldman. Alvin I. 1999. Knowledge in a Social World. Oxford: Clarendon Press. 
Jacobs, Scott. 2000. "Rhetoric and Dialectic from the Standpoint of Normative Pragmatics," Argumentation 14: 261-286.

Johnson, Ralph H. 2000. Manifest Rationality: A Pragmatic Theory of Argument. Mahwah, NJ: Lawrence Erlbaum Associates.

Meiland, Jack W. 1981. College Thinking: How to Get the Best Out of College. New York: Mentor (New American Library).

Pinto, Robert C. 2001. Argument, Inference and Dialectic. Dordrecht: Kluwer.

Snoeck Henkemans, A. Francisca 1992. Analysing complex Argumentation; The Reconstruction of Multiple and Coordinatively Compound Argumentation in a Critical Discussion. (Amsterdam: SicSat.

Tindale, Christopher W. 1999. Acts of Arguing: A Rhetorical Model of Argument. Albany: State University of New York Press.

Willard, Charles Arthur, 1989. A Theory of Argumentation. Tuscaloosa and London: University of Alabama Press. 